3 Research Square
Preprints are preliminary reports that have not undergone peer review.

They should not be considered conclusive, used to inform clinical practice, or referenced by the media as validated information.

\title{
The effect of government financial investment on the development of traditional medicine: Evidence from public Traditional Chinese Medicine hospitals (PTHs) of Henan Province, China
}

\author{
Weicun Ren \\ Zhengzhou university \\ Xiaoli Fu \\ Zhenhzhou University \\ Clifford Silver Tarimo \\ Zhengzhou University \\ Maisa Kasanga \\ Zhengzhou University \\ Yanqing Wang \\ Zhengzhou University \\ Jian Wu ( $\square$ jianwu17@163.com ) \\ https://orcid.org/0000-0003-2959-7448
}

\section{Research article}

Keywords: Governmental; Financial investment, TCM hospitals, Revenue

Posted Date: March 2nd, 2020

DOI: https://doi.org/10.21203/rs.3.rs-15565/v1

License: (c) (i) This work is licensed under a Creative Commons Attribution 4.0 International License. Read Full License 


\section{Abstract}

Background Traditional medicine has long been used to address relatively common illness, and Chinese government has been continually increasing its investments on Public Traditional Chinese Medicine hospitals (PTHs) in recent years. Objectives This study aimed to assess the scales and structure of investments on PTHs in Henan Province, China, in order to analyze the contribution of Government Financial Investment (GFI) to the revenue growth of PTHs, as well as raising practical investment strategies for decision-makers.

Methods This study was a panel data research, conducted in Henan Province, China. By collecting 143 PTHs' operational data from 2005 to 2017 , the authors computed data with Barrow Economic Growth Model (BEG), Stochastic Frontier Analysis (SFA) and Vector Autoregressive Model (VAR), respectively.

Results The study observed that the contribution of GFI to PTHs' revenue growth was positive (average MPG=2.84), which means the scale of GFI hadn't reached an optimal level. The scales of GFI on Grade III, Grade II A, Grade II B PTHs need to be increased by $-5.96 \%, 4.88 \%$ and $11.51 \%$ respectively in order to maximize the input-output efficiency. The third year after the investment year may be a more effective period for conducting an effect evaluation of GFI in Henan Province.

Conclusions GFI on PTHs usually has a long-term impact on PTHs. Government needs to adjust its GFI policy to maximize the input-output efficiency.

\section{Background}

Globally, traditional medicine has long been used to address relatively common illness [1], and Traditional Chinese medicine (TCM) is widely accepted in China as a complement and alternative for medical treatment $[2,3,4,5]$. But the contemporary private sectors which are the primary traditional medicine providers, appear to seek immediate cash payments that have frequently led to considerable debt and asset sales by traditional medicine users [6]. Government investment intervention is necessary if public traditional medicine hospitals that serve as "essential providers of last resort" tend to survive and to continue fulfilling their mission [7].

In past ten years in China, total government financial investment (GFI) in public TCM hospitals (PTHs) had reached 192.83 billion yuan, and it's currently mainly used for the improvement of house, maintenance of large medical equipment and the salary of staff. Henan Province is an agricultural and emerging industrial province with over 100 million people, a very typical and representative province in central China. In 2017 , the number of PTHs in Henan province reached 257, and the open beds were more than 63,100 , accounting for seven percent of the national total. The GFI reached 1.60 billion yuan in PTHs, accounting for $6.08 \%$ of the total GFI of Henan Province $[8,9]$.

Previous researches suggest that the support of GFI can affect the development of hospitals $[10,11]$. Woolhandler S et al. found that when experiencing severe cutbacks in funding for public medical facilities, the census at the county hospital, Highland General, has declined by 65 percent and the number of the outpatient visits have decreased by 50 percent [10]. Similarly, Shonick W observed both government health expenditures and hospital revenues had increased sharply, and the hospitals received government subsidies amounting to at least 60 percent of their total revenues [11].

Efficiency analysis in health care has attracted significant interest [12,13] due to escalating health care costs, especially in countries which public involvement in health care provision is high [14]. Increased efficiency is one way to bend the cost curve without compromising quality of care, which means it can get higher returns to fixed investment [15]. Compared with the least efficient hospitals, high-efficiency hospitals tended to have lower average costs, higher labor productivity, and higher profit margins [16].

Rhonda Kerr found that there are opportunities for public policies to support improved efficiency in public hospitals in Australia [17]. Roberto Colomb et al. found that ownership, specialization and size are determinants of all types of efficiency [18]. Chen et al. found that the changes introduced into the health care sector in China during the last thirty years have improved the cost efficiency of the whole system, especially after the public subsidies and medical insurance reforms [19].

This study analyzed the operational status of 143 PTHs in Henan Province from 2005 to 2017 by using the Barrow Economic Growth Model (BEG) to explore the scales and structure of PTHs' GFI based on promoting hospital revenue growth. The current input-output efficiency- maximizing investment strategy of GFI to PTHs was tested by using the stochastic frontier analysis (SFA). At the same time, the most appropriate evaluation period was also estimated based on the long-time impact trend of GFI on PTH's revenue growth by using Vector Autoregressive Model (VAR).

\section{Methods}

\section{Classification of public TCM institutions}


Public TCM institutions with less than 100 beds in China generally refer to community health service centers as primary health care institutions. Institutions with 100-500 beds are set as Grade II hospitals while Grade III hospitals refer institutions with more than 500 beds (5) (Table 1). Each grade was divided into A, B and C levels depending on department set, staffing, management level, technical level, work quality and technical facilities [20].

\section{Data Collection}

The data which was used in this study includes: TCM practicing clinical workers, suitable TCM technologies implemented, GFI, revenue and value of fixed assets of total 143 PTHs (including 23 Grade III, 96 Grade II A and 34 Grade II B) in Henan Province. All the data was derived from the Henan Provincial Health Statistics Yearbook and the hospital financial year reports from 2005 to 2017 . This study was submitted to Zhengzhou University Medical Ethics Committee and the need for ethics approval was waived.

\section{Data management and analysis}

\section{Variable index selection}

Considering the basic characteristics of PTHs and the effects of avoiding strong linear relationship between input indicators, the variables were selected based on importance and availability [21]. According to expert advice and requirements for the selected analysis model, this study selected the accepted indicators from five aspects of revenue, assets, technology, financial investment, personnel: 1 . The revenue of PTHs (Revenue); 2. Value of fixed assets (Fixed Assets); 3. No. of suitable TCM technologies implemented (Technologies); 4. Government financial investment (GFI); 5. No. of TCM practicing clinical workers (Clinical Workers).

\section{The scales and structure analysis method - Barrow Economic Growth Model (BEG)}

The BEG was derived from the theory of Endogenous Growth, which introduces government consumption based on the Cobb-Douglas production function [22], and was often used to explain economic growth of increasing economic returns and technical externalizations [23]. The specific form of the model can be expressed as:

$Y=A K^{\alpha} L^{\beta} G^{\delta}$

In formula:

Y: Revenue;

A: the technological progress rate (constant term coefficient);

K: Fixed Assets;

L: Clinical Workers;

G: GFI;

$a$ : the regression coefficients of variables $\mathrm{K}$, which is also the output elasticity of assets in growth of $\mathrm{Y}$, reflecting the contribution of variable $\mathrm{K}$ to the dependent variable $\mathrm{Y}$;

$\beta$ : the regression coefficients of variables $L$, which is also the output elasticity of labor in growth of $Y$, reflecting the contribution of variable $L$ to the dependent variable $Y$;

$\delta$ : the regression coefficients of variables $\mathrm{G}$, which is also the output elasticity of financial inputs in growth of $\mathrm{Y}$, reflecting the contribution of variable $\mathrm{G}$ to the dependent variable $\mathrm{Y}$.

The natural logarithm of the above formula can be obtained:

$\mathrm{L} n Y=C+a L n K+\beta \mathrm{L} n L+\delta L n G+\varepsilon$

Among them:

C: constant term;

$\varepsilon$ : the residual term;

$\left.\ln { }^{\star}{ }^{*}=" Y, K, L, G "\right):$ the logarithm of each variable, indicating the respective growth rates. 
In this study, the input-output elasticity of GFI to hospital revenue growth is $\delta$, and the marginal output of GFI is Marginal Product of Government (MPG). Following equation was used to get the marginal output and elasticity.

$$
M P G=\delta \frac{Y}{G}
$$

\section{Input-output efficiency analysis method-Stochastic Frontier Analysis (SFA)}

The SFA was first proposed by Aigner, Lovell and Schmidt (1977) and was widely used to estimate production functions or cost functions [14]. This study used SFA theory which was proposed by Fried based on traditional Data Envelopment Analysis model to explore the influence of environment and random factors on the evaluation object.

First, an input-oriented BCC model (a Barrow analysis model for variable-scale returns proposed by Banker, Charnes, and Cooper in 1984) [18] was established to measure the overall Input-output efficiency of PTHs under the influence of environmental and stochastic factors [24,25]. Secondly, SFA model was used to decompose the results of the BCC model, using slack variable $\mathrm{S}_{\text {ni }}$ (refers to the difference between the actual production process and the highest efficiency) of each input including Fixed Assets, Technologies and Clinical Workers as dependent variable and environmental factor variable GFI as independent variable, an SFA regression equation was established for each Sni [26,27,28,29,30]:

$\mathrm{S}_{n i}=\mathrm{f}^{n}\left(\mathrm{Z}_{n i} \cdot \beta^{n}\right)+\mathrm{v}_{n i}+\mu_{n i}$

In the formula:

$\mathrm{Z}_{n i}$ : GFI (environment variable);

$\beta^{n}$ : parameter which is estimated by environment variable;

$f^{n}$ : the influence of environmental variables to ;

$\mathrm{v}_{n i}:$ the mixed error term;

$\mathrm{v}_{\text {ni }}$. random interference term;

$\mu_{n i}$ : management inefficiency;

$n=1,2, \cdots, N, i=1,2, \cdots, l$.

\section{Evaluation period selection method - Vector Autoregressive Model (VAR)}

Based on the results of BEG, the VAR was used to estimate the most appropriate evaluation period of GFI by analyzing the long-term impact trend of Revenue and GFI on others or themselves. By building an impulse response function, the random error terms imposed on an endogenous variable GFI and the impact on PTHs' GFI and Revenue were analyzed, characterizing the response from the variable to a certain error change.

\section{Analysis tool}

The initial data was collected and processed by using Excel 2016. DEA and SFA analysis were performed by using DEAP2.1 and FORNT41 software, respectively. BEG and VAR were performed by using Eviews6.0 software. $\mathrm{P}<0.05$ was considered statistically significant.

\section{Results}

\section{Operational Information of PTHs}

Between 2005 and 2017, the Clinical Workers of total 143 PTHs in Henan Province increased from 32058 to 64669, with an average annual growth rate of $6.02 \%$; the Fixed Assets increased with an average annual growth rate of $15.61 \%$; the Revenue increased from 1.83 billion yuan to 16.37 billion yuan, with an average annual growth rate of $20.02 \%$; while the GFI increased from 0.14 billion yuan to 1.61 billion yuan, with an average annual growth rate of $22.97 \%$ (Table 2 ).

Table 3 displays the descriptive statistics of Grade II A, Grade II B and Grade III PTHs in 2017 and includes information on Fixed Asset, Clinical Workers, Technologies and GFI.

\section{Scales and structure analysis of PTHs' GFI based on Revenue promotion}


The Augmented Dickey-Fuller test method (ADF) was selected to perform the unit root test of the time series of each variable in the model. During the test process, variables without time trend term and constant term were selected for testing. Table 4 shows that the ADF value of the secondorder difference result (D2) that the statistical value of each variable was smaller than critical value of the critical level (0.05), indicating that the second-order difference sequences of the four variables were stable, that was, all four variables were second-order single-integer sequences.

Therefore, the model could be co-integrated.

The main purpose of the co-integration test was to judge the rationality and correctness of model's set, and thus effectively avoided the pseudoregression of the model. Since the model contains four variables, the Johansen test method was used for co-integration test. In the test form of the model, the test was selected in the form of both trend and intercept terms. It can be seen from Table 5 that at the $5 \%$ significance level, both the tracking test and the $\lambda$-Max statistic tests display that there were three co-integration vectors between four variables, that is, there was a cointegration relationship between variables. This showed that the linear combination of four variables had long-term stability, and the model can be further analyzed.

\section{Scales and structure analysis}

In this study, the regression analysis was performed on the model by Ordinary Least Squares method. The regression results were as follows:

Ln $Y=-1.4433+1.5218 \mathrm{LnK}-1.4157 \mathrm{LnL}+0.2503 \mathrm{LnG}$

$(-0.7498)(1.7453)(-0.8210)(1.6261)$

$\mathrm{R}^{2}=0.9858 \quad \mathrm{DW}=1.0740$

It can be seen from the above regression results that the $\mathrm{R}^{2}$ value of the model was 0.99 , indicating that the model had good goodness of fit and the linear relationship between variables was relatively significant.

According to regression results, the hypothesis of $M P G=\delta Y / G$ can be obtained as MPG $=0.25 Y / G$. The average value of $Y / G$ in $T P H s$ from 2005 to 2017 were 11.35 , so the average MPG=2.84 (the minimum value was 1.82 and the maximum value was 3.46 ).

Since the MPG value was greater than 1, GFI scales of PTHs hadn't yet reached the optimal level according to the "Baro Law". In addition, from $M P G>0$, it can be seen that the GFI had a positive economic impact on promoting the growth of PTHs' revenue.

\section{Efficiency-maximizing investment strategy of GFI on PTHs}

\section{Input-output efficiency analysis}

The SFA model was used to analyze the impact of GIF on the input-output efficiency of input factors: Fixed Assets, Clinical Workers and Technologies. In three types of PTHs, management factor () was the main factor affecting Fixed Assets and Clinical Workers ( $\mathrm{Y} \approx 1, \mathrm{P}<0.05)$. $\mathrm{Y}$ values in the input relaxation equations of Technologies in Grade III PTHs were approximately equal to 1 but not pass the t-test, indicating that difference between the management factor and the random error() had little impact on the efficiency, but it had an impact on the direction of efficiency.

Further analysis found increasing the GFI will reduce the efficiency of Grade III PTHs $(\beta>0, P<0.05)$, but will improve the efficiency of Grade II B PTHs $(\beta<0, P<0.05)$. In Grade II A PTHs, increasing the GFI will reduce the waste of Fixed Assets and Clinical Workers $(\beta<0, P<0.05)$, but it will intensify the waste of Technologies $(\beta>0, P<0.05)$. See Table 6 and Table 7 for details.

\section{The efficiency-maximizing investment strategy of GFI}

Based on the results of table 6 and table 7, this study explored the efficiency-maximizing investment strategy of GFI in three types of PTHs. We found that in order to achieve maximum input-output efficiency, Grade III, Grade II A and Grade II B PTHs' GFI need to increase -5148, 9263 and 2034 million-yuan, accounting for $-5.96 \%, 4.88 \%$ and $11.51 \%$ of current amount, respectively. Similarly, the study also described the Investment strategy of Fixed Assets and Clinical Workers corresponding to GFI (Table 8).

This study created a VAR model with four variables including: Revenue, Fixed Assets, Clinical Workers and GFI of PTHs, and analyzed the impulse response function based on this. The specific results show that the change of GFIs' scale has a cyclical decrease trend in its long-term impact, and its overall cumulative impact was almost zero. Generally speaking, in China, the current changes in GFI will not affect the scale of future GFI, which makes it simple and feasible to adjust the current GFI according to the efficiency-maximizing investment strategy (Figure 1).

\section{The most appropriate evaluation period of GFI}


The study also analyzed the most appropriate evaluation period based on the long-time impact trend of GFI on PTH's revenue growth by using VAR. As shown in Figure 2, firstly, GIF had a positive impact on PTHs' revenue, and the impact will gradually decline after the third period (one year as a period in PTHs, generally). Secondly, this positive economic impact began to zero after the 17th period. In short, the GFI had a significant role in promoting the revenue growth of PTHs, and the third year after the investment year may be a more effective period for conducting an effect evaluation of GFI in Henan Province.

\section{Discussions}

This study found that the MPG value of GFI to PTHs' revenue was greater than 1 between 2005 and 2017, indicating the optimal GFI scales hasn't yet been reached. Schlenker $T$ found that the traditional medical providers were included in the Medicaid Waivers to help achieving the "Triple Aim" goals in the United States Texas [31]. It's suggested that the government should carry out sustainable strategic design when designing and arranging hospital investment, and allocate sufficient resources which will help to effectively address patient needs, technological changes and increased acumen [32,33]. The growth of fixed assets also has a positive impact on PTHs' revenue growth [16]. And fixed assets have the greatest promotion impact on PTH's revenue growth of the three variables of GFI, fixed assets and clinical workers. It shows that if the PTHs' GFI can be more applied to infrastructure construction and equipment purchase, it can promote the increase in PTHs' revenue to a greater extent.

Previous studies have suggested that GFI has an impact on the efficiency of different-scale PTHs' input-output, and the degree of impact is related to characteristics of hospital and market [34,35]. This study found that increasing GFI would reduce the input-output efficiency of Grade III PTHs.

For Grade II PTHs, increasing GFI would increase the efficiency of Fixed Assets and Clinical Workers. One likely reason for this phenomenon is that, large-scale and high-tech hospitals have sufficient funds, while hospitals with limited size and technology are limited in source channels, and rely more on government support [36]. Therefore, focusing the GFI on smaller traditional medicine hospitals will contribute to the development of traditional medicine [37].

Simultaneously, the impact of GFI on PTHs' revenue have been steadily weakening, lasting about $17^{\text {th }}$ period, and the overall impact was positive. If the impact on the current GFI is to be evaluated, the impact evaluation within a single investment period (one year in China) is suitable for the next third period to obtain the maximum value. And the overall impact evaluation should be conducted after the $17^{\text {th }}$ period. Governments and hospitals should carefully formulate GFI impact evaluation plan and select appropriate evaluation cycles to accurately assess the effectiveness of GFI.

This study attempted to estimate the current state and the efficiency-maximizing investment strategy of PTH's GFI from one of the most populated provinces of China. We recommend future studies to stress on the classification criteria of hospital categories based on the size of the beds rather than the official classification criteria. And the time span of data collection can be further extended to improve the accuracy and credibility of the analysis results. Furthermore, there is also room for optimization in the selection of indicators.

\section{Conclusions}

The GFI for TCM has experienced a period of rapid growth of the past 12 years, but there is no strong evidence that its actual impact is consistent with the expected target. Although our analysis was limited to PTHs, it provided important evidence that GFI can impact the input-output efficiency of traditional hospitals and promote its development, and governments need to make evaluation period decision carefully. Our findings can provide new evidence and decision-making basis for governments to develop policies that promote the development of traditional medicine and increase the supply of traditional medicine services.

\section{Abbreviations}

TCM: Traditional Chinese Medicine;

GFI: Governmental financial investment;

PTHs: Public TCM hospitals;

SFA: Stochastic Frontier Analysis;

BEG: Barrow Economic Growth Model;

Revenue: The revenue of PTHs;

Clinical Workers: No. of TCM practicing clinical workers;

Fixed Assets: Value of fixed assets; 
Technologies: No. of suitable TCM technologies implemented;

MPG: Marginal Product of Government;

ADF: Augmented Dickey-Fuller.

\section{Declarations}

Ethics approval and consent to participate Not applicable

Consent to publish Not applicable

Availability of data and materials All data generated and analysed during this study are included in this published article.

Competing interests The authors declare that they have no competing interests.

Funding This research was supported by: National Key R\&D Program of China "Digital diagnosis and treatment equipment research and development pilot project" (2018YFC0114501). The funder had no role in study design, data collection and analysis, decision to publish, or preparation of the manuscript.

Authors' Contributions JW designed the study, WR, XF and MK built the model, led the data analysis and writing of the manuscript. WY and CST contributed to the data collection, statistical analysis and interpretation. All authors read and approved the final manuscript.

Acknowledgements The authors would like to thank the Henan Provincial Health and Family Planning Commission for their support for making this study possible.

Authors' Information Weicun Ren, 1. College of Public Health, Zhengzhou University; 2. College of Sanquan, Xinxiang Medical University; E-mail: 1742823089@qq.com.

Xiaoli Fu, College of Public Health, Zhengzhou University; E-mail: xlfu66@126.com.

Clifford Silver Tarimo, 1.College of Public Health, Zhengzhou University; 2. Dares Salaam Institute of Technology, Department of Science and Laboratory Technology, Tanzania; E-mail: cliffordtarimo94@gmail.com.

Maisa Kasanga, 1.College of Public Health, Zhengzhou University; 2. University Teaching Hospital, Zambia E-mail: kasangamaisa@yahoo.co.uk.

Yanqing Wang, College of Public Health, Zhengzhou University; E-mail: 892551926@qq.com.

Corresponding Author: Jian Wu, College of Public Health Zhengzhou University

100 Science Avenue Gaoxin District, Zhengzhou City, Henan Province, China P.R. 450001; E-mail: jianwu17@163.com.

\section{References}

1. Evans DB, Hsu J, Boerma T. Universal health coverage and universal access. Bulletin of the World Health Organization. 2013;91(5):546.

2. Fan XQ, Meng FL, Wang DH, et al. Perceptions of traditional Chinese medicine for chronic disease care and prevention: a cross-sectional study of Chinese hospital-based health care professionals. BMC COMPLEM ALTERN M. 2018;18(1):1-9.

3. Allen P, Cao Q, Wang HF. Public hospital autonomy in China in an international context. Int J Health Plan Mgmt. 2014;29(2):141-159.

4. Zhou F, Yufang Hao YF, Guo H, et al. Attitude, Knowledge, and Practice on Evidence-Based Nursing among Registered Nurses in Traditional Chinese Medicine Hospitals: A Multiple Center Cross-Sectional Survey in China. EVID-BASED COMPL ALT. 2016;1741(427X):1-8.

5. National Health and Family Commission. Yearbook of Traditional Chinese Medicine of China. Chinese Medicine Press, 2011.

6. Bandeth R, Gillian L, Barbara MP, Suzanne F. The commercialization of traditional medicine in modern Cambodia. Health Policy and Planning. 2018;33(4):9-16.

7. Falik M. Hospital financial viability: When is government intervention appropriate? HEALTH SERV RES. 1983;18(4):582-586.

8. .National Health commission of the People's Republic of China. Statistical Bulletin of the Development of China's Health Care Industry in 2017. 2017. http://www.nhc.gov.cn/guihuaxxs/s10743/201806/44e3cdfe11fa4c7f928c879d435b6a18.shtml. Accessed 17 Dec 2019.

9. State Administration of Traditional Chinese Medicine of the People's Republic of China. 2017 National Traditional Chinese Medicine Statistics Extract. 2017. http://www.satcm.gov.cn/. Accessed 17 Dec 2019.

10. Woolhandler S, Himmelstein DU, Silber R, et al. Public money, private control: a case study of hospital financing in Oakland and Berkeley, California. Ame J of Pub Health. 1983;73(5):584-587.

11. Shonick W. The public hospital and its local ecology in the United States: some relationships between the "plight of the public hospital" and "the plight of the cities." Int J Health Serv. 1979;9(1):359-396.

12. Worthington AC. Frontier efficiency measurement in health care: a review of empirical techniques and selected applications. Med Care Res Rev. 2004;61(2):135-170.

Page $7 / 12$ 
13. Jacobs R, Smith P, Street A. Measuring efficiency in health care: analytic techniques and health policy. Economica. 2010;77(305):205-206.

14. Yildiz MS, Heboyan V, Khan MM. Estimating technical efficiency of Turkish hospitals: implications for hospital reform Initiatives. BMC HEALTH SERV RES. 2018;18:2-16.

15. Michael R, Herbert SW. Characteristics of High- and Low-Efficiency Hospitals. MED CARE RES REV. 2018;75(4):454-478.

16. Karen S, Palmer AD, Brown JM. Standardising costs or standardising care? Qualitative evaluation of the implementation and impact of a hospital funding reform in Ontario, Canada. HEALTH RES POLICY SY. 2018;16(1):2-15.

17. Martin A, Hartman M, Benson X. National health spending in 2014: Faster growth driven by coverage expansion and prescription drug spending. HEALTH AFF. 2016;35(1):150-160.

18. Roberto C, Gianmaria M, Giorgio V. Determinants of transient and persistent hospital efficiency: The case of Italy. HEALTH ECON. 2017;26(2):5-22.

19. Chen Z, Barros CP, Hou X. Has the medical reform improved the cost efficiency of Chinese hospitals? Soc Sci J. 2016;53(4):10-20.

20. National Health commission of the People's Republic of China. Medical Institution Review Method. 2011. http://www.nhc.gov.cn/fzs/s3576/201808/0415d028c18a-46c4a316d8339edcdf44.shtml. Accessed 17 Dec 2019.

21. Kerr R, Hendrie DV. Is capital investment in Australian hospitals effectively funding patient access to efficient public hospital care? AUST HEALTH REV. 2018;42(5):501-513.

22. Barro RJ. Government Spending in a simple Model of Endogenous Growth. J POLIT ECON. 1990;98(1):103-125.

23. Wolf A. The Economics and finance of Higher Education. Int ENC EDU. 2010;25(3):573-58.

24. Charnes A, Cooper WW, Rhodes E. Measuring the efficiency of decision making units. Eur J Oper Res. 1978;15(3):429-44.

25. Bernet P, Rosko M, Valdmanis V. The relationship between hospital cost inefficiency and debt ratings. Int J Health Care Financ Econ. 2008;34(2):66-88

26. Battese GE, Coelli TJ. A model for technical inefficiency effects in a stochastic frontier production function for panel data. Empir Econ. 1955;20(2):32-35.

27. Aigner D, Lovell CAK, Schmidt P. Formulation and estimation of stochastic frontier production function models. J Econ. 1977;6(1):21-37.

28. Ali E, Madjid T, Hosseinzadeh LF, et al. A three-stage Data Envelopment Analysis model with application to banking industry. Measurement. 2014;49(4):308-319.

29. Yang J, Lu JY. Environmental investment efficiency in China based on three-stage DEA model. Journal of Systems Engineering. 2012;10(5):699-711.

30. Huang W. Environment, risk and enterprise technical efficiency: A modified three-stage DEA model. System Engineering Theory and Practice. 2012;14(1):1-10.

31. Schlenker T, Huber CA. A Unique Funding Opportunity for Public Health in Texas. J Public Health Man and Pra. 2015;21(3):81-86.

32. Duckett SJ. The Australian health care system: reform, repair or replace? Aust Health Rev. 2008;32(2):322-329.

33. Abel AB, Mankiw NG, Summers LH, Zeckhauser RJ. Assessing dynamic efficiency: theory and evidence. Rev Econ Stud. 1989;56(1):1-19.

34. Carey K. Hospital cost efficiency and system membership. Inq a J Med care Organ Provis Financing. 2003;40(1):25-38.

35. Mutter R, Valdmanis V, Rosko M. High versus lower quality hospitals: a comparison of environmental characteristics and technical efficiency. Health Serv Outcomes Res Methodol. 2010;10(4):134-153.

36. Yi HM, Miller G, Zhang LX, et al. Intended and unintended consequences of China's zero markup drug policy. Health Aff. 2015;34(8):13911398.

37. Kim TH, Mccue MJ. Association of Market, Operational, and Financial Factors with Nonprofit Hospital Capital Investment. Inquiry. 2008;45(2):215-231.

\section{Tables}

Table 1 Classification of TCM medical institutions

\begin{tabular}{|c|c|c|c|}
\hline Classification & Beds & Responsibilities & District \\
\hline Grade I & $\leqq 99$ & Provide prevention, medical, health care, and rehabilitation services & Single community \\
\hline Grade II (A, B) & $100-500$ & Provide comprehensive medical and health services and undertake certain teaching and research tasks & Multiple communities \\
\hline Grade III & $>501$ & Provide high-level specialist health services and perform higher education and research tasks & Several areas \\
\hline
\end{tabular}


Table 2 The operational information of sample PTHs

\begin{tabular}{|c|c|c|c|c|c|}
\hline Year & $\begin{array}{l}\text { Clinical Workers }{ }^{\mathrm{a}} \\
\text { (10000 person) }\end{array}$ & $\begin{array}{l}\text { Fixed Assets }^{b} \\
\text { (billion yuan) }\end{array}$ & $\begin{array}{l}\text { Revenue }^{\mathrm{c}} \\
\text { (billion yuan) }\end{array}$ & $\begin{array}{l}\text { GFI }^{\mathrm{d}} \\
\text { (100 million yuan) }\end{array}$ & $\begin{array}{l}\text { GFI/Revenue } \\
\text { (\%) }\end{array}$ \\
\hline 2005 & 3.21 & 2.33 & 1.83 & 0.14 & 7.65 \\
\hline 2006 & 3.34 & 2.64 & 1.99 & 0.16 & 8.04 \\
\hline 2007 & 3.27 & 2.56 & 2.45 & 0.20 & 8.16 \\
\hline 2008 & 3.49 & 2.95 & 3.23 & 0.27 & 8.36 \\
\hline 2009 & 3.70 & 3.57 & 4.01 & 0.45 & 11.22 \\
\hline 2010 & 3.82 & 4.10 & 4.93 & 0.68 & 13.79 \\
\hline 2011 & 4.31 & 5.10 & 6.35 & 0.67 & 10.55 \\
\hline 2012 & 4.62 & 6.22 & 8.38 & 0.61 & 7.28 \\
\hline 2013 & 5.04 & 7.48 & 9.96 & 0.78 & 7.83 \\
\hline 2014 & 5.68 & 9.04 & 12.28 & 0.90 & 7.33 \\
\hline 2015 & 6.12 & 10.33 & 13.37 & 1.19 & 8.90 \\
\hline 2016 & 6.42 & 12.09 & 14.55 & 1.54 & 10.58 \\
\hline 2017 & 6.47 & 13.26 & 16.37 & 1.61 & 9.84 \\
\hline Average annual growth rate & $6.02 \%$ & $15.61 \%$ & $20.02 \%$ & $22.97 \%$ & $9.20 \%$ \\
\hline
\end{tabular}

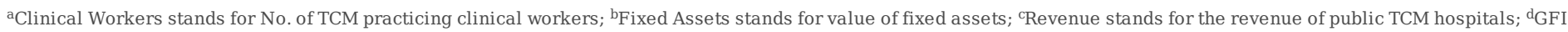
stands for governmental financial investment

Table 3 Characteristics of PTHs' efficiency evaluation indexes

\begin{tabular}{|c|c|c|c|c|c|c|}
\hline \multirow[t]{3}{*}{ Hospital grade } & \multirow[t]{3}{*}{ Sample size } & \multirow[t]{3}{*}{ Indicators } & \multicolumn{3}{|l|}{ Input indicators } & \multirow{2}{*}{$\begin{array}{l}\text { Environmental factor } \\
\text { GFI }\end{array}$} \\
\hline & & & Fixed Assets & Clinical Workers & Technologies & \\
\hline & & & 100 million yuan & 100 persons & items & 100 million yuan \\
\hline \multirow[t]{4}{*}{ Grade III } & 23 & $\operatorname{Max}^{\mathrm{a}}$ & 4.45 & 21.25 & 40.00 & 5.16 \\
\hline & & $\operatorname{Min}^{b}$ & 0.97 & 5.75 & 10.00 & 0.22 \\
\hline & & $\mathrm{AVG}^{\mathrm{c}}$ & 1.99 & 11.46 & 25.70 & 2.38 \\
\hline & & $\mathrm{SD}^{\mathrm{d}}$ & 1.311 & 6.95 & 12.54 & 2.45 \\
\hline \multirow[t]{4}{*}{ Grade II A } & 96 & Max & 3.29 & 8.25 & 33.00 & 3.08 \\
\hline & & Min & 0.53 & 0.75 & 9.00 & 0.05 \\
\hline & & AVG & 0.80 & 3.61 & 17.26 & 0.92 \\
\hline & & SD & 0.37 & 1.75 & 14.57 & 1.02 \\
\hline \multirow[t]{4}{*}{ Grade II B } & 24 & Max & 1.06 & 2.90 & 20.00 & 2.98 \\
\hline & & Min & 0.32 & 0.60 & 8.00 & 0.19 \\
\hline & & AVG & 0.42 & 1.50 & 17.22 & 0.76 \\
\hline & & $\mathrm{SD}$ & 0.18 & 0.70 & 13.29 & 0.85 \\
\hline
\end{tabular}

${ }^{\mathrm{a}}$ Max stands for Maximum; ${ }^{\mathrm{b}}$ Min stands for Minimum; ${ }^{\mathrm{C} A V G}$ stands for Average; ${ }^{\mathrm{d}} \mathrm{SD}$ stands for Standard deviation 
Table 4 Unit root test results of variables $(0.05)$

\begin{tabular}{|lllllll|}
\hline \multirow{2}{*}{ variable } & \multicolumn{2}{l}{ Level test result } & \multicolumn{2}{l}{ First-order difference result (D) } & \multicolumn{2}{l|}{ Second-order difference result (D2) } \\
\cline { 2 - 6 } & ADF value & Critical value & ADF value & Critical value & ADF value & Critical value \\
\hline LN Y & 1.7439 & -1.9777 & -0.4981 & -1.9777 & -3.9300 & -1.9823 \\
\hline LN K & 7.6575 & -1.9740 & -0.1238 & -1.9823 & -5.9347 & -1.9823 \\
\hline LN L & 4.9011 & -1.9740 & -1.2430 & -1.9777 & -5.2242 & -1.9823 \\
\hline LN G & 4.0416 & -1.9740 & -1.2776 & -1.9777 & -2.8411 & -1.9823 \\
\hline
\end{tabular}

Table 5 Co-integration test results between multiple variables

\begin{tabular}{|lllc|}
\hline Original hypothesis & Eigenvalue & Trace $(P)$ & $\lambda$-Max Eigenvalue $(P)$ \\
\hline No co-integration vector & 1.0000 & $338.3943(0.0001)$ & $267.6401(0.0001)$ \\
\hline At most one co-integration variable & 0.9870 & $70.7542(<0.0001)$ & $47.7566(<0.0001)$ \\
\hline At most two co-integration variable & 0.7941 & $22.9976(0.0006)$ & $17.389(0.0037)$ \\
\hline At most three co-integration variable & 0.3998 & $5.6147(0.0212)$ & $5.6147(0.0212)$ \\
\hline
\end{tabular}

Table 6 The impact of GIF on the efficiency of input factors

\begin{tabular}{|c|c|c|c|c|c|c|c|c|c|}
\hline \multirow{2}{*}{$\begin{array}{l}\text { Independent } \\
\text { variable }\end{array}$} & \multicolumn{3}{|l|}{ Fixed Assets } & \multicolumn{3}{|c|}{ Clinical Workers } & \multicolumn{3}{|l|}{ Technologies } \\
\hline & Grade III & Grade II A & Grade II B & Grade III & Grade II A & Grade II B & Grade III & Grade II A & Grade II B \\
\hline $\begin{array}{l}\text { Constant } \\
\text { term }\end{array}$ & $\begin{array}{l}0.56 \mathrm{E}+01 * * * 0.12 \mathrm{E}+01 \\
0.30 \mathrm{E}+01\end{array}$ & $\begin{array}{l}0.22+01 * * * \\
0.66 \mathrm{E}+00 \\
0.94 \mathrm{E}+01\end{array}$ & $\begin{array}{l}0.46 \mathrm{E}+01 * * * \\
0.76 \mathrm{E}+00 \\
0.86 \mathrm{E}+01\end{array}$ & $\begin{array}{l}0.18 \mathrm{E}+01^{* *} \\
0.86 \mathrm{E}+00 \\
0.24 \mathrm{E}+01\end{array}$ & $\begin{array}{l}0.11 \mathrm{E}+01 * * * \\
0.76 \mathrm{E}+00 \\
0.61 \mathrm{E}+01\end{array}$ & $\begin{array}{c}0.07 \mathrm{E}+01 * * * \\
0.10 \mathrm{E}+00 \\
0.36 \mathrm{E}+02\end{array}$ & $\begin{array}{l}0.32 \mathrm{E}+01 * * * \\
0.82 \mathrm{E}+00 \\
0.39 \mathrm{E}+01\end{array}$ & $\begin{array}{l}0.32 \mathrm{E}+01^{* *} \\
0.18 \mathrm{E}+01 \\
0.19 \mathrm{E}+01\end{array}$ & $\begin{array}{c}0.28 \mathrm{E}+01 \\
0.19 \mathrm{E}+01 \\
0.96 \mathrm{E}+00\end{array}$ \\
\hline GFI & $\begin{array}{l}0.32 \mathrm{E}+00 * * * 0.52 \mathrm{E}-01 \\
0.60 \mathrm{E}+01\end{array}$ & $\begin{array}{l}-0.63 \mathrm{E}- \\
01 * * 0.49 \mathrm{E}- \\
01 \\
-0.13 \mathrm{E}+01\end{array}$ & $\begin{array}{c}-0.10 \mathrm{E}+00 * * \\
0.92 \mathrm{E}-01 \\
-0.17 \mathrm{E}+01\end{array}$ & $\begin{array}{l}0.40 \mathrm{E}-01 * * * \\
0.66 \mathrm{E}-01 \\
0.61 \mathrm{E}+01\end{array}$ & $\begin{array}{l}-0.20 \mathrm{E}- \\
01 * * 0.58 \mathrm{E}- \\
01 \\
-0.35 \mathrm{E}+01\end{array}$ & $\begin{array}{l}-0.41 \mathrm{E}-01 * * * \\
0.80 \mathrm{E}-02 \\
-0.51 \mathrm{E}+01\end{array}$ & $\begin{array}{l}0.79 \mathrm{E}-01 \\
0.69 \mathrm{E}-01 \\
0.89 \mathrm{E}+00\end{array}$ & $\begin{array}{l}0.90 \mathrm{E}- \\
01 * * 0.63 \mathrm{E}- \\
010.14 \mathrm{E}+01\end{array}$ & $\begin{array}{l}-0.25 \mathrm{E}- \\
01 * * 0.13 \mathrm{E}- \\
01 \\
-0.19 \mathrm{E}+01\end{array}$ \\
\hline$\delta^{2}$ & $\begin{array}{l}0.11 \mathrm{E}+00 * * * 0.32 \mathrm{E}-01 \\
0.35 \mathrm{E}+01\end{array}$ & $\begin{array}{l}0.32 \mathrm{E}+00 * * * \\
0.47 \mathrm{E}-01 \\
0.68 \mathrm{E}+01\end{array}$ & $\begin{array}{l}0.77 \mathrm{E}+00^{* *} \\
0.35 \mathrm{E}+00 \\
0.22 \mathrm{E}+01\end{array}$ & $\begin{array}{l}0.11 \mathrm{E}+01 * * * \\
0.44 \mathrm{E}+00 \\
0.25 \mathrm{E}+01\end{array}$ & $\begin{array}{c}0.44 \mathrm{E}+00^{*} \\
0.32 \mathrm{E}+00 \\
0.14 \mathrm{E}+01\end{array}$ & $\begin{array}{l}0.92 \mathrm{E}+00^{* * *} \\
0.92 \mathrm{E}-01 \\
0.10 \mathrm{E}+02\end{array}$ & $\begin{array}{c}0.27 \mathrm{E}+00 \\
0.25 \mathrm{E}+00 \\
0.11 \mathrm{E}+01\end{array}$ & $\begin{array}{l}0.67 \mathrm{E}+00 * * * \\
0.93 \mathrm{E}-01 \\
0.72 \mathrm{E}+01\end{array}$ & $\begin{array}{l}0.45 \mathrm{E}+00 * * * \\
0.13 \mathrm{E}+00 \\
0.35 \mathrm{E}+01\end{array}$ \\
\hline$\gamma$ & $\begin{array}{l}0.95 \mathrm{E}+00 * * * 0.74 \mathrm{E}-01 \\
0.13 \mathrm{E}+02\end{array}$ & $\begin{array}{l}0.88 \mathrm{E}+00^{* * *} \\
0.36 \mathrm{E}-01 \\
0.25 \mathrm{E} * * *\end{array}$ & $\begin{array}{l}0.90 \mathrm{E}+00 * * * \\
0.14 \mathrm{E}+00 \\
0.62 \mathrm{E}+01\end{array}$ & $\begin{array}{l}0.95 \mathrm{E}+00 * * * \\
0.85 \mathrm{E}-01 \\
0.64 \mathrm{E}+01\end{array}$ & $\begin{array}{l}0.91 \mathrm{E}+00 * * * \\
0.61 \mathrm{E}-01 \\
0.50 \mathrm{E}+01\end{array}$ & $\begin{array}{l}0.99 \mathrm{E}+00^{* * *} \\
0.20 \mathrm{E}-05 \\
0.50 \mathrm{E}+06\end{array}$ & $\begin{array}{l}0.90 \mathrm{E}+00 \\
0.51 \mathrm{E}-01 \\
0.72 \mathrm{E}+01\end{array}$ & $\begin{array}{l}0.99 \mathrm{E}+00^{* * *} \\
0.11 \mathrm{E}-04 \\
0.95 \mathrm{E}+05\end{array}$ & $\begin{array}{l}0.87 \mathrm{E}+00 * * \\
0.18 \mathrm{E}-01 \\
0.42 \mathrm{E}+01\end{array}$ \\
\hline $\begin{array}{l}\text { Likelihood } \\
\text { function } \\
\text { absolute } \\
\text { value }\end{array}$ & $-0.75 E+01$ & $-0.81 E+02$ & $-0.20 \mathrm{E}+02$ & $-0.13 E+02$ & $-0.82 \mathrm{E}+02$ & $-0.16 \mathrm{E}+02$ & $-0.22 \mathrm{E}+02$ & $-0.12 \mathrm{E}+03$ & $-0.24 E+02$ \\
\hline $\begin{array}{l}\text { Unilateral } \\
\text { error } \\
\text { likelihood } \\
\text { ratio test }\end{array}$ & $0.74 \mathrm{E}+01$ & $0.13 \mathrm{E}-01$ & $0.89 \mathrm{E}+00$ & $0.69 \mathrm{E}-01$ & $0.77 \mathrm{E}-01$ & $0.47 \mathrm{E}+01$ & $0.16 \mathrm{E}+01$ & $0.24 \mathrm{E}+01$ & 1 \\
\hline
\end{tabular}

$*_{\square * *} * * *$ indicate significant levels at $0.1,0.05$, and 0.01 , respectively. The values below the horizontal line are test values, $P$ values, variances, respectively. 
Table 7 Influence direction of GFI on PTHs input indicators (0.05)

\begin{tabular}{|llll|}
\hline Hospital grade & Fixed Assets & Clinical Workers & Technologies \\
\hline Grade III & $\square^{\mathrm{a}}$ & $\square$ & \\
Grade II A & $+^{\mathrm{b}}$ & + & \\
Grade II B & $+^{+}$ & + & + \\
\hline
\end{tabular}

a"+" means that the increase in GFI will increase the efficiency of input utilization; " "-" means that the increase in GFI will increase the waste of input

Table 8 The efficiency-maximizing investment strategy

\begin{tabular}{|c|c|c|c|c|c|}
\hline \multirow[t]{4}{*}{ Hospital grade } & \multirow{3}{*}{$\begin{array}{l}\text { GFI } \\
\text { Increment }^{\mathrm{a}} \\
\left(\%{ }^{\mathrm{b}}\right)\end{array}$} & \multicolumn{2}{|l|}{ Fixed Assets } & \multicolumn{2}{|c|}{ Clinical Workers } \\
\hline & & Increment & Eliminate the increment after GFI impact $\left(\%^{c}\right)$ & Increment & Eliminate the increment after GFI impact (\%) \\
\hline & & $(\%)$ & & $(\%)$ & \\
\hline & 100 million & 100 million yuan & 100 million & 100 persons & 100 persons \\
\hline Grade III & $-51.48(-5.96)$ & $5.26(11.49)$ & $4.58(-1.49)$ & $26.34(9.99)$ & $24.26(-0.79)$ \\
\hline Grade II A & $92.63(4.88)$ & $9.99(13.01)$ & $13.23(4.22)$ & 41.55 (11.99) & $47.44(1.70)$ \\
\hline Grade II B & $20.34(11.51)$ & $1.28(17.66)$ & $2.49(7.04)$ & $5.28(14.67)$ & $6.84(4.33)$ \\
\hline
\end{tabular}

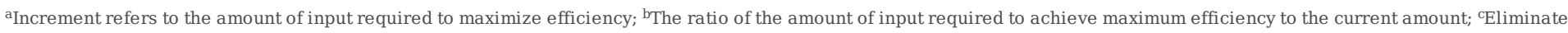
the ratio of inputs affected by GFI to the current amount

\section{Figures}

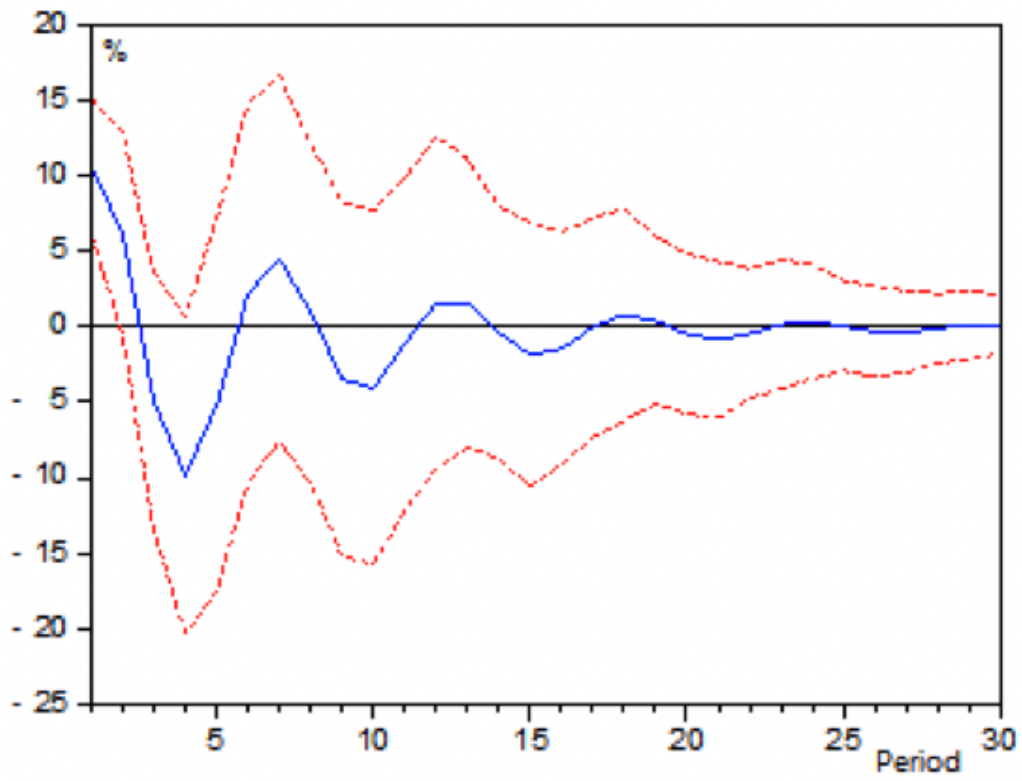

Figure 1 
Impulse response of GFI to its own changes The horizontal axis represents the duration period of the impulse response function, and the vertical axis represents the responsiveness of PTHs' GFI to GIF changes. The solid line in the middle represented the impulse response function, and the dotted line represented the deviation from the standard deviation of two times

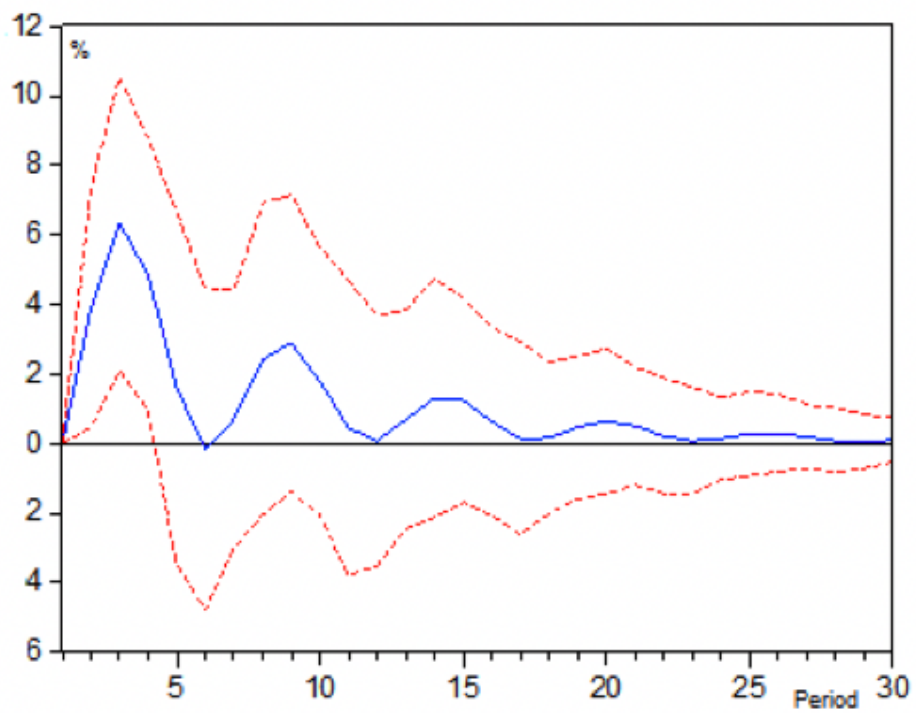

\section{Figure 2}

Impulse response of Revenue to GFI The horizontal axis represents the duration period of the impulse response function, and the vertical axis represents the responsiveness of PTHs' revenue to GIF changes. The solid line in the middle represented the impulse response function, and the dotted line represented the deviation from the standard deviation of two times 